\title{
Realization of the innovative potential of radial-shear rolling for forming the structure and mechanical properties of AISI-321 austenitic stainless steel
}

\author{
Abdrakhman Naizabekov ${ }^{1}$, Sergey Lezhnev ${ }^{1}$, Evgeniy Panin ${ }^{2}$,
} Irina Volokitina ${ }^{1}$, Andrey Kasperovich ${ }^{3}$

\author{
${ }^{1}$ Department of Metallurgy and Mining, Rudny Industrial Institute, 50 let Oktyabrya 38, 111500, Rudny, Kostanay re- \\ gion, Kazakhstan. \\ ${ }_{2}^{2}$ Metal Forming department, Karaganda Industrial University, Republic avenue 30, 101400, Temirtau, Karaganda region, \\ Kazakhstan. \\ ${ }^{3}$ Belarusian State Technological University, Sverdlov str. 13a, 220006, Minsk, Belarus. \\ e-mail: naizabekov57@mail.ru
}

\begin{abstract}
In this paper the grain structure and mechanical properties of AISI-321 austenitic stainless steel subjected to 7 passes of radial-shear rolling at $1000{ }^{\circ} \mathrm{C}$ were investigated. The tensile strength (1076 MPa) and Vickers microhardness $(322 \mathrm{HV})$ after 7 passes increased by 2.2 times and 2 times, respectively, relative to the initial annealed state (480 MPa, $160 \mathrm{HV})$. Ultra-fine grained structure $(200-700 \mathrm{~nm})$ formed in the bar section area from its surface to a depth of 0.25 of the radius. The transition zone is located in the area between $0.5 \mathrm{R}$ and $0.25 \mathrm{R}$ of the bar section. Anything deeper is a rolling texture. The 7-pass radial-shear rolling process is an effective way to form UFG structure and improved mechanical properties in AISI-321 austenitic stainless steel.
\end{abstract}

Keywords: severe plastic deformation, ultra-fine grained structure, radial-shear rolling, microstructure, mechanical properties.

\section{INTRODUCTION}

In an era of accelerated development of scientific and technological progress, the issue of obtaining new metal materials with an improved set of mechanical, physical and operational properties is very relevant. One of the ways to increase the strength of a structural material is to grind its microstructure to an ultra-finegrained state [1]. Such materials, due to their small grain size, contain a large number of grain boundaries in the structure, which affect their mechanical and physical properties. At the same time, the grain boundaries should be predominantly large-angle, and the grains should be equiaxed, with dimensions less than 1 micron.

From all methods for producing ultra-fine-grained materials, the most promising is severe plastic deformation (SPD) [2-6], due to the possibility of obtaining isotropic products of a large volume without internal discontinuities. But, unfortunately, with the simultaneous increase in strength properties in ultrafine materials, there is an inevitable decrease in its plastic properties. Such material becomes brittle and is subjected to destruction. The use of metal materials with a gradient structure [7-10], where the grain size from the coarse-grained state in the central part of the workpiece decreases to the ultra-fine-grained state on the surface, is an effective way to solve the problem of the plasticity increasing of metal products.

In addition, most methods of obtaining isotropic UFG materials by severe plastic deformation methods do not allow obtaining a sufficient volume of UFG materials with dimensions for commercial products. So, such well-studied methods of SPD implementation as: high-pressure torsion (HPT) [11-12]; equal-channel angular pressing (ECAP) [13-14] in a large number of different matrix designs [15-20] and many other methods have critical limitations on the length of the obtained workpiece, which significantly complicates its industrial application [21]. Further development of the scientific direction related to severe plastic deformation is associated with the development of new innovative methods for producing long-length products from ferrous and non-ferrous metals with an ultrafine-grained structure. These methods include: Conform method [22, 23]; equal-channel angular sheet drawing [24]; combined processes "ECAP-drawing" 
[25], "rolling-ECAP" [26] and many others.

To solve the problem of obtaining long-length metal products (round bars) with increased strength and plasticity, i.e. with a gradient structure, it is possible by using radial-shear rolling [27-28]. The difference between this method of rolling and conventional cross-screw rolling is that in this case a single round bar is rolled according to a three-roll scheme with increased roll feed angles, which contributes to the intensification of shear deformation and non-monotonicity of the metal flow under the prevailing hydrostatic compression scheme [1]. Such conditions are favorable for the formation of a gradient structure, especially at low deformation temperatures. Therefore, this method of deformation has a great potential for producing long-length metal products with a gradient structure, since, unlike other methods, it is as simple, effective and technological as possible.

\section{COMPUTER SIMULATION}

The purpose of this work is to study the process of radial-shear rolling of AISI-321 austenitic stainless steel and identify the features of its influence on the microstructure evolution and mechanical properties.

The choice of material is justified by the fact that austenitic stainless steel is a fairly often used structural material that is used in the manufacture of various parts for responsible purposes, working in many cases in extreme operating conditions.

The study was conducted in two stages. At the first stage, computer simulation was performed in Simufact Forming software. At the second stage, a physical experiment was performed on the SVP-08 radialshear rolling mill.

To create a model of radial-shear rolling, it was decided to use the parameters of the existing SVP-08 mill installed at Rudny Industrial Institute. The initial billet with a diameter of $30 \mathrm{~mm}$ and a length of 150 $\mathrm{mm}$ was rolled on a mill with a compression of $3 \mathrm{~mm}$. The material of billet was AISI-321 austenitic stainless steel $(0.08 \%$ C, $17-19 \% \mathrm{Cr}$; 9-11 \% Ni; $2 \% \mathrm{Mn} ; 0.8 \% \mathrm{Si}$; 0.5-0.7 \% Ti). Since the initial recrystallization temperature for the selected steel is $1020{ }^{\circ} \mathrm{C}$ [29], the heating temperature was $800{ }^{\circ} \mathrm{C}$, for excluding the recrystallization process; the rolling speed was equal to $50 \mathrm{rpm}$, as the nominal value on SVP-08 mill. The friction coefficient at the contact of workpiece and rolls was assumed 0.5.

During the model calculation (figure 1) the billet was captured by rolls of SVP-08 mill and rolled to a diameter of $27 \mathrm{~mm}$. Final dimensions of the workpiece after rolling were as follows: diameter $27 \mathrm{~mm}$ and length $185,2 \mathrm{~mm}$.

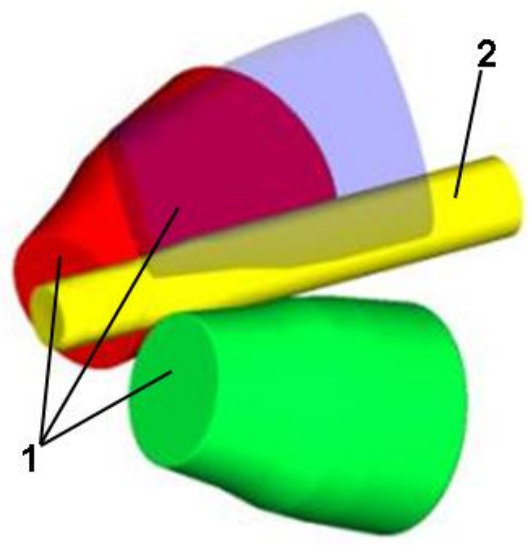

Figure 1: Model of radial-shear rolling in Simufact Forming software: 1 - rolls of SVP-08 mill; 2 - billet

To assess the effectiveness of the workpiece processing at cross-section, the parameter "equivalent strain" was considered, which is often named as "accumulated strain" in various sources. The reason for this is that this is a cumulative parameter, i.e. this parameter is not reset after the load is removed. Also, to determine the level of processing of the initial metal structure, the average grain size was determined, the initial size of which was equal to 40 microns.

Since radial-shear rolling is a cross-section type of rolling, it is advisable to study the strain state both in the longitudinal and cross section of the workpiece - this will allow to evaluate not only the value of this parameter, but also the nature of its distribution over the cross-section. When analyzing the workpiece after rolling (figure 2), it was found that the distribution of equivalent deformation fully corresponds to the crosssection type of deformation when the workpiece rotates around its axis, since the cross-section clearly shows 
the ring zones of processing.

At the same time, it should be noted that the distribution of the equivalent strain in the radial direction is rather high. In the axial zone $(0 \div 35 \%$ of the radius from the center), the strain level is about 0.45 . In the intermediate zone (35 $\div 80 \%$ of the radius from the center), the intensity of shear deformation increases, here the level of deformation is $0.5 \div 0.55$. In the surface zone $(80 \div 100 \%$ of the radius from the center), the maximum effect of shear deformation is observed, here the deformation level is $0.6 \div 0.65$.
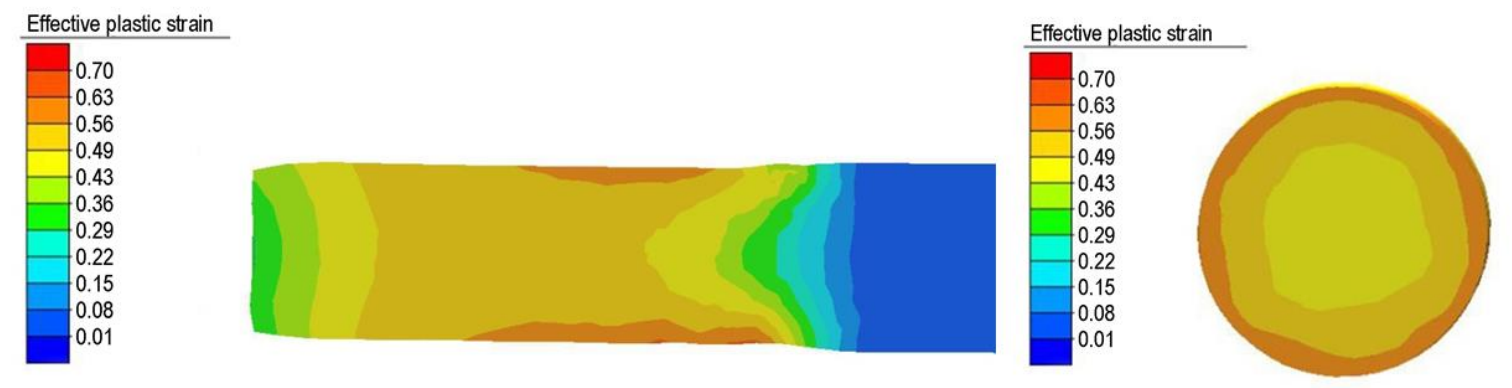

Figure 2: Equivalent strain

According to the work [30], the value of accumulated strain during radial-shear rolling can be calculated using the formula:

$$
\varepsilon=2 \ln \left(\frac{d_{0}}{d_{1}}\right)+\ln \left(\frac{90}{\gamma}\right),
$$

where $\mathrm{d}_{0}$ - diameter of the workpiece before rolling;

$\mathrm{d}_{1}$ - diameter of the workpiece after rolling;

$\gamma$ - the angle of the helix rising, which is determined depending on the angle of the conical part of the roll. In our case, for the angle of the conical part of $3^{\circ}$, the angle of the helix rising will be equal to $70^{\circ}$.

However, this formula allows to calculate the value of strain only in the axial zone of the workpiece. To find the strain values in the peripheral and surface zones, the formula (1) will look like:

$$
\varepsilon=2 \ln \left(\frac{d_{0}}{d_{1}}\right)+\left(1+\frac{K}{100}\right) \cdot \ln \left(\frac{90}{\gamma}\right),
$$

where $\mathrm{K}$ - percentage distance of the beginning of the corresponding zone from the center of the workpiece.

The formula for determining the equivalent strain in the peripheral zone will be as follows:

$$
\varepsilon=2 \ln \left(\frac{d_{0}}{d_{1}}\right)+1,35 \ln \left(\frac{90}{\gamma}\right),
$$

In the surface zone, the value of the equivalent strain will be determined by the formula:

$$
\varepsilon=2 \ln \left(\frac{d_{0}}{d_{1}}\right)+1,8 \ln \left(\frac{90}{\gamma}\right),
$$

Using formulas (1), (3), (4) the following results were obtained: the value of the equivalent strain in the axial zone $\varepsilon_{\mathrm{AX}}=0.46$; in the peripheral zone $\varepsilon_{\mathrm{PER}}=0.54$; in the surface zone $\varepsilon_{\mathrm{SURF}}=0.66$. As it can be seen, the results of the calculation using formulas are very close to the simulation results, which indicates the high accuracy of the model.

Simufact Forming uses the Yada algorithm described in detail in work [31] to model the microstructure evolution. The essence of this algorithm is that during deformation 2 types of recrystallization (static and dynamic) are calculated, which affect the initial grain size change. Dynamic recrystallization calculation is a part of the model that concerns processes in the deformation zone. It starts when the equivalent strain exceeds the critical strain. The main value of this model is the Zener-Hollomon parameter. 
Static recrystallization calculation is a part of the model when the considered workpiece segment is not located in the deformation zone. The calculation is performed as long as the static recrystallization is not interrupted by the deformation stage or phase transition.

When considering the microstructure evolution (figure 3), it was noted that radial-shear rolling is a very effective method of AISI-321 austenitic stainless steel processing. At the same time, it was noted that the distribution of this parameter over the section of the workpiece is almost identical to the equivalent strain. After one pass, the grain size decreased from 40 microns to 35 microns in the axial zone; in the peripheral zone, due to the intensification of shear deformations, the grain size was about 29 microns. The minimum grain size, equal to 24 microns, was revealed in the surface zone, where the impact of shear deformations is the most intense. Thus, the difference in grain size values across the section of the workpiece reaches 11 microns. This fact allows us to speak about the formation of gradient structure during the implementation of radial-shear rolling - the surface layers of the workpiece get the highest structure processing, while the central layers are processed much less intensively.
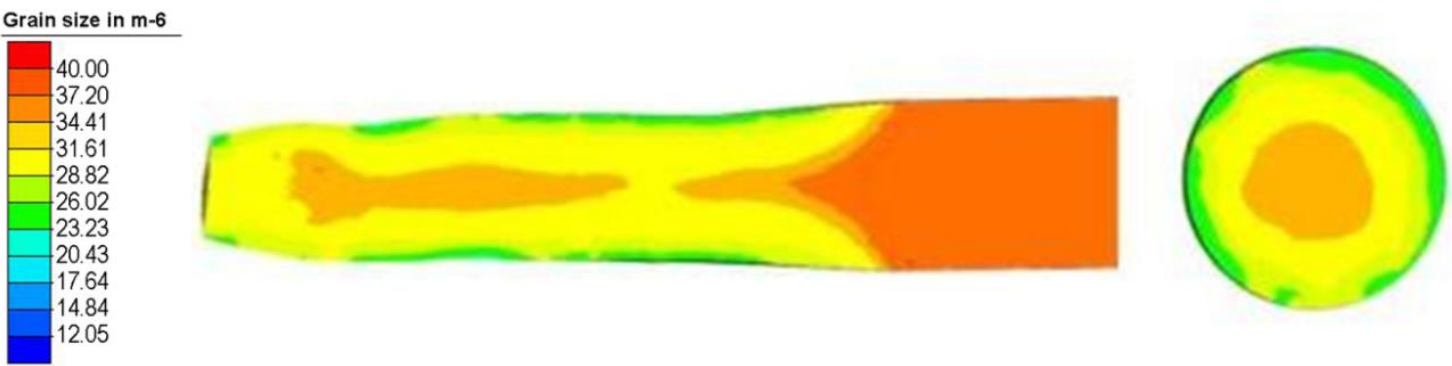

Figure 3: Grain size change

\section{EXPERIMENTAL PROCEDURE}

At the second stage, during the physical experiment, bars made of AISI-321 stainless austenitic steel were rolled on SVP-08 radial-shear rolling mill in 7 passes from the initial diameter of $30 \mathrm{~mm}$ to a diameter of 13 $\mathrm{mm}$. Based on the results of computer simulation obtained in [32-33], the bars were rolled at the standard rotation speed of the rolls $50 \mathrm{rpm}$, preheating them to a temperature of $800{ }^{\circ} \mathrm{C}$. When the required diameter $13 \mathrm{~mm}$ was reached, in accordance with the results of the studies given in work [34], intensive cooling of the rod with water was performed.

The microstructure was studied using a transmission electron microscope JEM-1400Plus with a lower camera OneView that provides increased brightness, clarity and contrast of images even from dark areas at an accelerating voltage of $200 \mathrm{kV}$. Samples were prepared by electrolytic method in a solution $(600 \mathrm{ml}$ Methanol, $360 \mathrm{ml}$ Butylcellosolve, $60 \mathrm{ml}$ Perchloric Acid). The microstructure was studied in the center, periphery and surface of the bar section. A diagram of sample cutting and microstructure research is shown in figure 4. The EBSD analysis was performed using Auriga CrossBeam-540 scanning electron microscope, which is equipped with Nordlyss NL04-3015-20 EBSD analyzer.

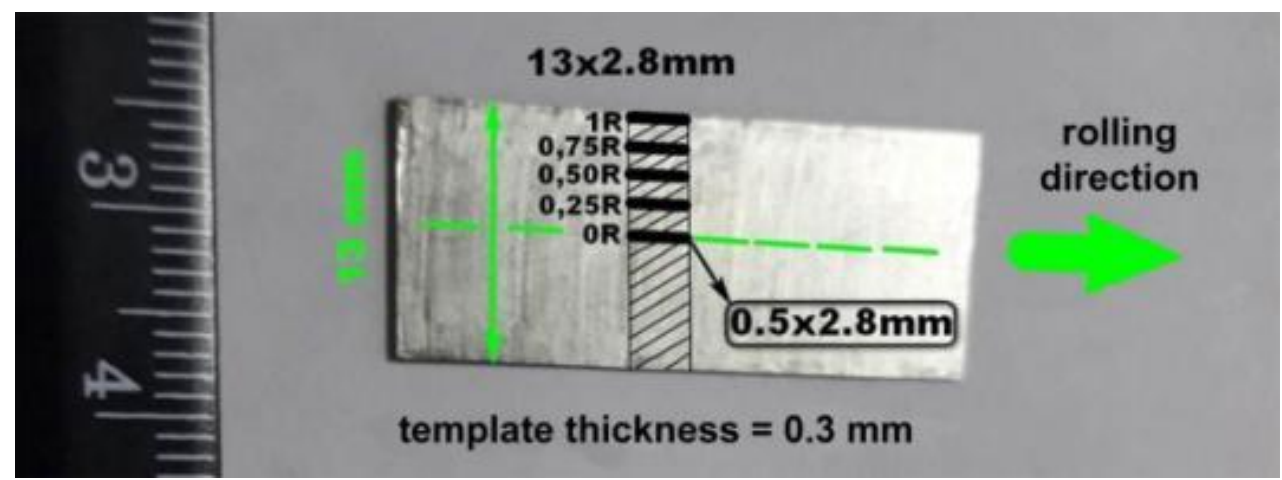

Figure 4: Scheme of samples cutting for TEM-analysis

\section{RESULTS AND DISCUSSION}

\subsection{Microstructure study}

The microstructure of AISI-321 steel after radial-shear rolling is shown in figure 5. The figure shows sections of the structure along the sample cross section at different distances from the center. 
The study of the structure by sample cross-section at different distances from the center showed that the structure is heterogeneous. From the edge to the depth of 0.75 radius (figure $5 \mathrm{a}, \mathrm{b}$ ), an ultra-fine-grained structure with equiaxed grains of $200-700 \mathrm{~nm}$ in size is observed. The orientation of the grains, as it can be seen at the diffractogram from $1 \mathrm{R}$ section (figure $5 \mathrm{f}$ ), is random without a pronounced texture in one direction or another. This indicates that the properties of this zone are quasi-isotropic at the macro scale.
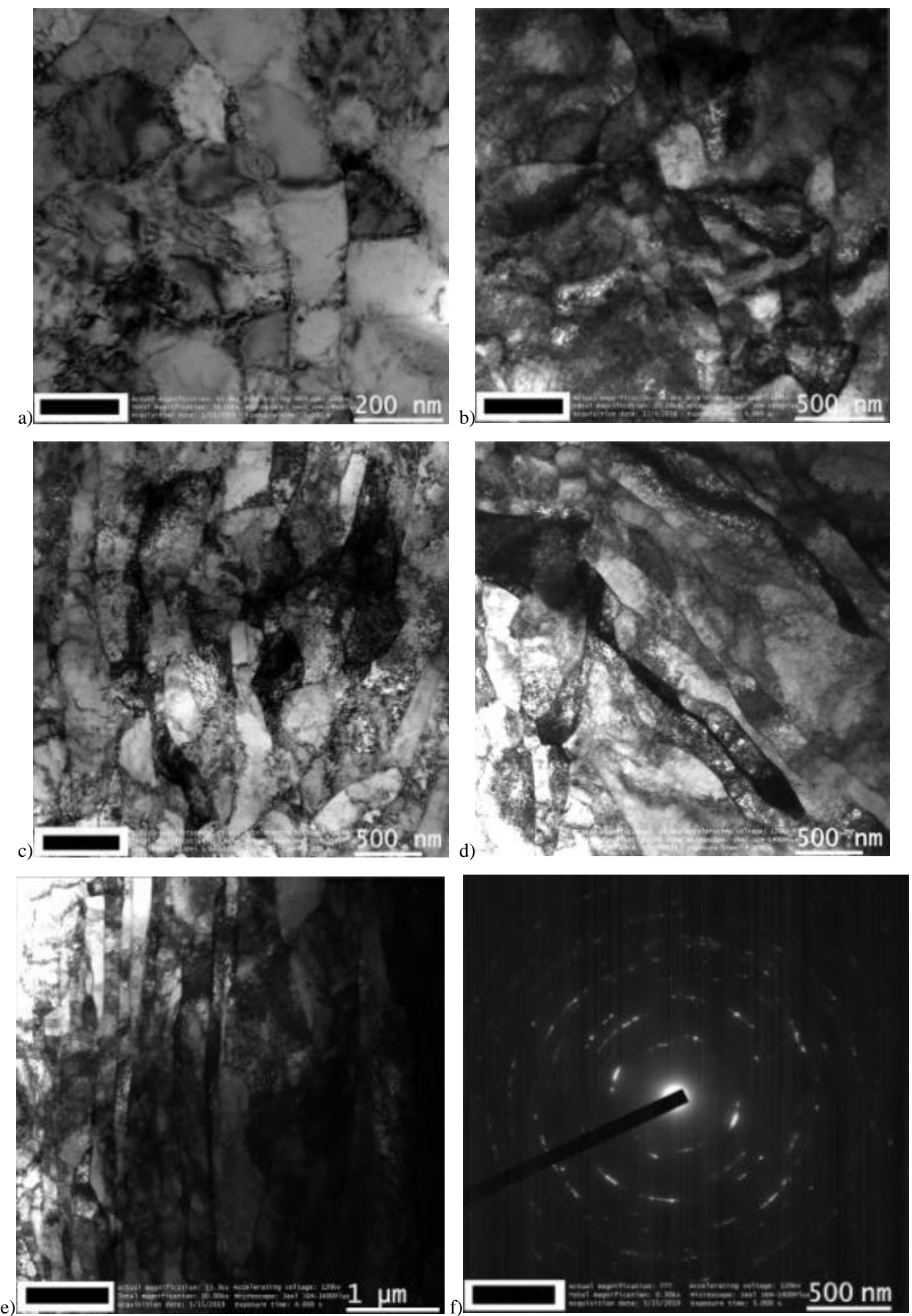

Figure 5: Microstructure of AISI-321 steel after radial-shear rolling: a) $1 \mathrm{R}$ (edge); b) $0.75 \mathrm{R}$; c) $0.5 \mathrm{R}$; d) $0.25 \mathrm{R}$; e) $0 \mathrm{R}$ (center); f) diffractogram from 1R section 
At a depth of 0.5 radius (figure $5 \mathrm{c}$ ), there is a tendency to pull the grains along the rolling direction. However, compared to the axial zone $0 \mathrm{R}$ (figure $5 \mathrm{e}$ ), the grains retain a greater angle of disorientation and their length is much smaller. Also, there are no straight knife borders that are clearly visible in the axial zone, which are characteristic of strong uniaxial deformation. It can be assumed that the eddy metal flow, characteristic of the outer zones, at a depth of 0.5 radius fades and the axial direction of the metal flow begins to prevail.

At a depth of 0.25 radius (figure $5 \mathrm{~d}$ ), very long elongated grains with clear boundaries are observed. However, in some places there are small grains strongly disoriented with the axial direction of the flow. In general, the structure is oriented with a greater degree of axial deformation than in the $0.5 \mathrm{R}$ zone, since the transition zone between structures of different types is between $0.5 \mathrm{R}$ and $0.25 \mathrm{R}$ of the bar section, capturing the $0.5 \mathrm{R}$ area. It can be assumed that the transition zone is localized in the area of $0.5-0.3 \mathrm{R}$ of the bar section, since the structure of the zone $0.25 \mathrm{R}$ is morphologically closer to the structure $0 \mathrm{R}$ (the center of the bar section) than the structure of the area $0.5 \mathrm{R}$ to the structure of the area $0.75 \mathrm{R}$ of the bar section. The $0 \mathrm{R}$ axial zone shown in figure $5 \mathrm{e}$ is a rolling texture.

In general, the boundary of the distribution of an equiaxed UFG structure is defined by 0.75 of the radius. However, not only the size and shape of the grains have great importance, but also the orientation of the crystal lattice in them. This parameter can be estimated by the nature of the location of the diffractogram reflexes. If the set of reflexes from the polycrystalline region is evenly distributed over the corresponding circles as in figure $5 \mathrm{f}$, then the crystal lattice in the grains is randomly oriented in each grain. If the reflexes are grouped and merged into short strips along the vertices of a hexagon or square relative to the central reflex, depending on the type of grid, then there is a texture whose direction can be determined by the angle at which the vertices of the shapes forming the diffractogram are rotated. However, the grain disorientation can be evaluated much more clearly using the electron back-scattered diffraction (EBSD) method. The results of EBSD analysis for different zones are shown in figure 6.
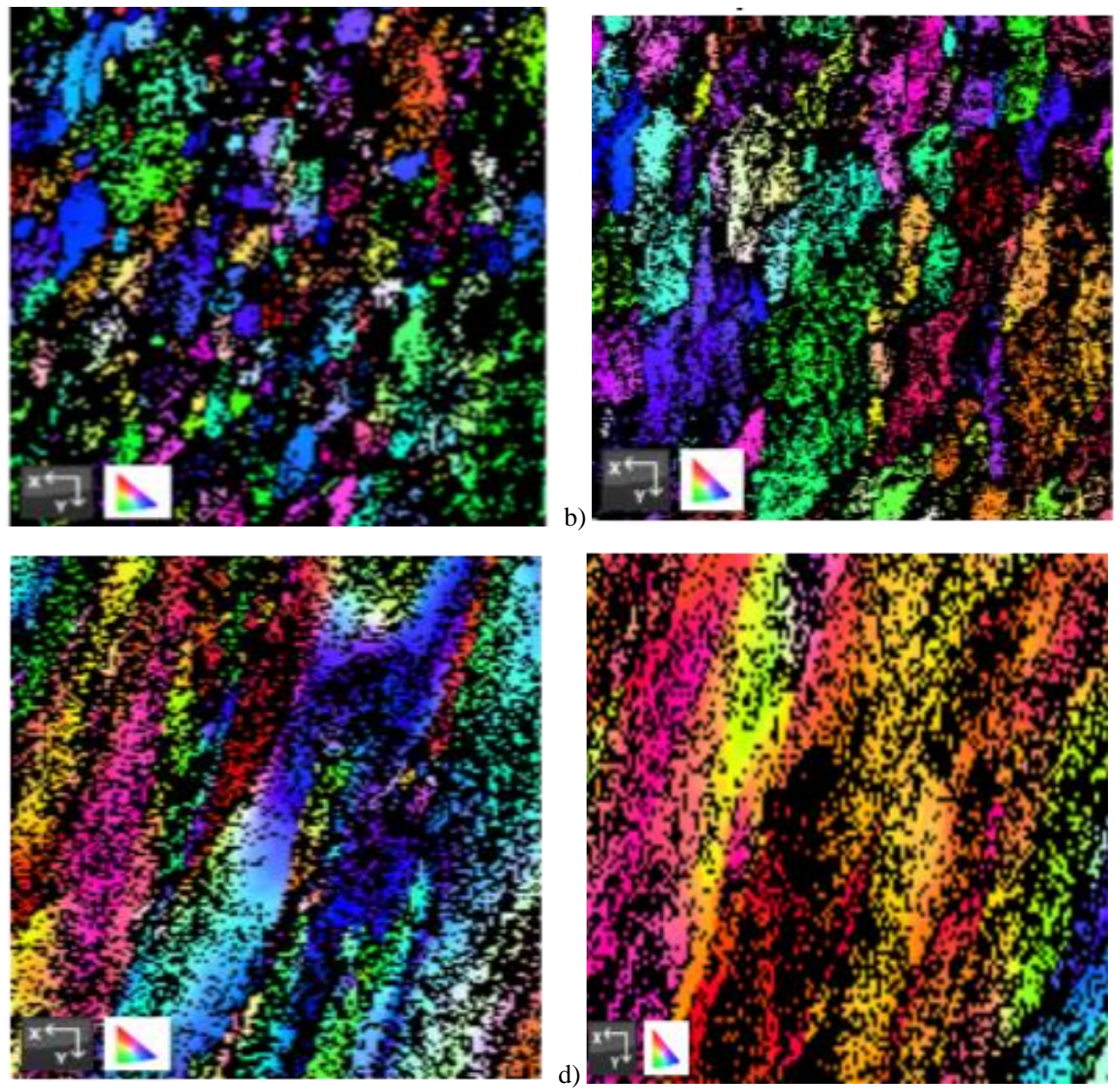

Figure 6: EBSD analysis: a) 1R (edge); b) $0.75 \mathrm{R}$; c) $0.25 \mathrm{R}$; d) $0 \mathrm{R}$ (center) 
The EBSD analysis confirms the conclusion made when analyzing images from a transmission electron microscope, including the assumption of a large number of high-angle intergrain boundaries in the peripheral parts of the rod up to a depth of 0.75 radius.

\subsection{Mechanical properties investigation}

After metallographic analysis, a microhardness study was performed. Microhardness measurements were performed on a Hysitron TI Premier nanoindenter equipped with a Vickers microhardness indenter (HV). The initial microhardness of a $30 \mathrm{~mm}$ diameter bar made of AISI-321 steel was $160 \mathrm{HV}$. After 7 passes of radial-shear rolling, the microhardness level was increased to 288-321 $\mathrm{HV}$.

Further, the study of mechanical properties after each pass of radial-shear rolling was carried out. The mechanical properties were determined by testing flat samples on the Instron 5966 test machine. The test was carried out at a tensile speed of $0.5 \mathrm{~mm} / \mathrm{min}$, the working part of the sample was $16 \mathrm{~mm}$. 3 duplicate samples were taken for the tensile test for each pass. The results of measurements of all mechanical properties for each pass are presented in the graphs form in figure 7.

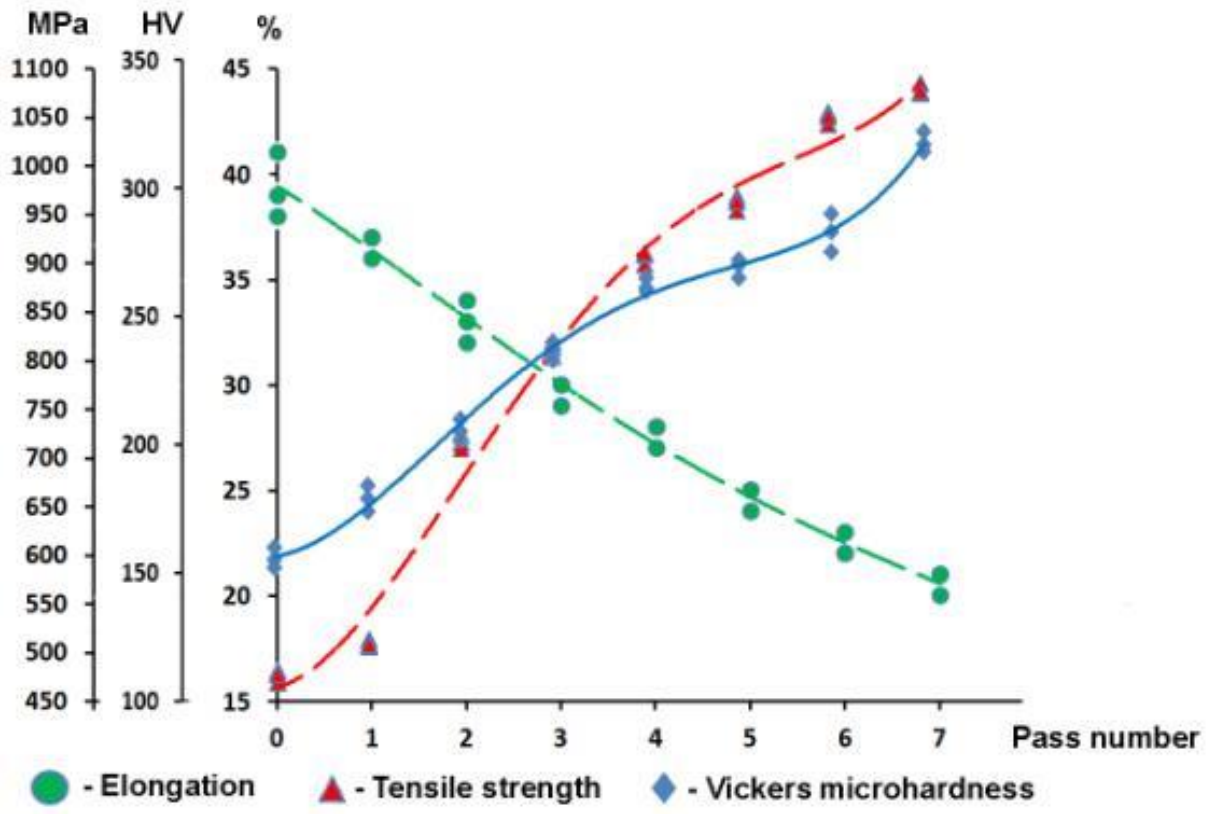

Figure 7: Mechanical properties of AISI-321 austenitic stainless steel after radial-shear rolling by passes

It can be concluded that the mechanical properties change monotonously depending on the pass number. At the same time, the tensile strength increases almost 2 times to a value of $1073 \mathrm{MPa}$, and the elongation, which is one of the material plasticity indicators, is also reduced by 2 times, reaching $21 \%$, against the initial $40 \%$. The decrease of elongation in this case is within the normal range for materials that are processed by such deformation type and is comparable to the known data, for example, when deforming this material by ECAP method [35].

Taking into account the predicted microstructure heterogeneity at large deformations, it was decided to investigate the microhardness change along the cross section of the bar for the last 7 th pass. In order to build a microhardness profile, measurements were made through each millimeter of the sample section 3 times at each point. Results for each point were averaged. The graph of microhardness change along the cross section is shown in figure 8 .

The highest hardness $(321 \mathrm{HV})$ is observed at a distance of $1 \mathrm{~mm}$ from the edge of the bar. On the surface, there is a slight decrease in microhardness by 5-8 HV. This phenomenon can be explained by the decarburization of the outer layer due to the heating of the sample during rolling. As expected, due to structural heterogeneity in the cross section of the bar, there is a smooth drop in the microhardness level of the central zone of the bar by $10.2 \%(33 \mathrm{HV})$. 


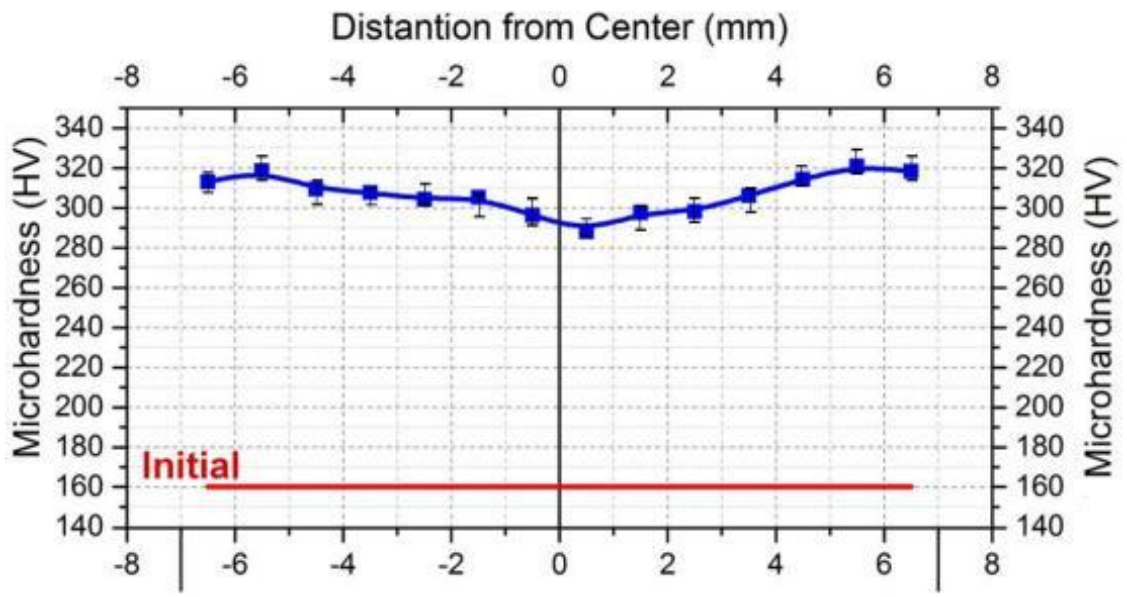

Figure 8: Microhardness of AISI-321 austenitic stainless steel in cross section after 7 passes

\section{CONCLUSION}

1. Computer simulation of the radial-shear rolling process has shown that during deformation along the section of the workpiece, the metal is processed very unevenly - the surface layers of the workpiece get the highest structure processing, while the central layers are processed much less intensively.

2. According to the results of metallographic and EBSD analyses, it can be concluded that the ultrafine grained structure $(200-700 \mathrm{~nm})$ formed in the bar section area from its surface to a depth of 0.25 of the radius. The transition zone is located in the area between $0.5 \mathrm{R}$ and $0.25 \mathrm{R}$ of the bar section. Anything deeper is a rolling texture. The results of metallographic studies are also confirmed by the microhardness study.

3. The results obtained in the course of computer simulation and physical experiment on deformation of AISI-321 stainless austenitic steel on a radial-shear rolling mill indicate the gradient nature of the structure formed in the resulting bars.

\section{ACKNOWLEDGEMENTS}

This work was carried out within the framework of the theme № AP05131382 "Development and research of technology for obtaining ultrafine materials with improved mechanical properties and increased radiation resistance for use as materials of the first wall of thermonuclear reactors and in nuclear power" under the grant funding program for scientific and (or) scientific and technical projects for 2018-2020 in the Republic of Kazakhstan.

\section{BIBLIOGRAPHY}

[1] VALIEV, R.Z., ISLAMGALIEV, R.K., ALEXANDROV, I.V., "Bulk nanostructured materials from severe plastic deformation", Progress in Materials Science, v. 45, n. 2, pp. 103-189, Feb. 2000.

[2] VERLEYSEN, P., LANJEWAR, H., "Dynamic high pressure torsion: A novel technique for dynamic severe plastic deformation", Journal of Materials Processing Technology, v. 276, article number 116393, Feb. 2020.

[3] WANG, P., YIN, T., QU, S., "On the grain size dependent working hardening behaviors of severe plastic deformation processed metals", Scripta Materialia, v. 178, pp. 171-175, Mar. 2020.

[4] QI, Y., KOSINOVA, A., KILMAMETOV, A.R., et al., "Stabilization of ultrafine-grained microstructure in high-purity copper by gas-filled pores produced by severe plastic deformation", Scripta Materialia, v. 178, pp. 29-33, Mar. 2020.

[5] MANJUNATH, G.K., PREETHAM KUMAR, G.V. UDAYA BHAT, K., "Evolution of Tribological Properties of Cast Al-10Zn-2Mg Alloy Subjected to Severe Plastic Deformation", Lecture Notes in Mechanical Engineering, pp. 165-175, July 2019.

[6] YIN, Y., JIA, W., LI, S., et al., "Mechanical Behavior of Nanostructured Metallic Materials Prepared by Severe Plastic Deformation", Materials China, v. 38, n. 10, pp. 1030-1036, Oct. 2019.

[7] RAAB, G.I., SIMONOVA, L.A., ALESHIN G.N., "Tailoring the gradient ultrafine-grained structure in low-carbon steel during drawing with shear", Metalurgija, v. 55, n. 2, pp. 177-180, Feb. 2016.

[8] YAN, X., MENG, X., LUO, L., et al., "Mechanical behaviour of AZ31 magnesium alloy with the lami- 
nate and gradient structure”, Philosophical Magazine, v. 99, n. 24, pp. 3059-3077, Dec. 2019.

[9] GONG, Y., GU, J., NI, S., et al., "A good combination of strength and ductility of ultra-coarse-grained $\mathrm{Cu}-\mathrm{Al}$ alloy with coarse-grained surface layer via pre-torsional treatment", Micron, v. 129, article number 102783, Feb. 2020.

[10] RAAB, G.I., KODIROV, I.S., ALESHIN, G.N., et al., "Influence of features of gradient structure formation during intensive plastic deformation of alloys with different types of crystal lattice", Bulletin of Nosov Magnitogorsk State Technical University, v. 17, n. 1, pp. 64-75, Jan. 2019.

[11] ZHILYAEV, A.P., LANGDON, T.G. "Using high-pressure torsion for metal processing: Fundamentals and applications", Progress in Materials Science, v. 53, n. 6, pp. 893-979, Aug. 2008.

[12] ZHILYAEV, A.P., NURISLAMOVA, G.V., KIM, B.K., et al., "Experimental parameters influencing grain refinement and microstructural evolution during high-pressure torsion”, Acta Materialia, v. 51, n. 3, pp. 753-765, Feb. 2003.

[13] VALIEV, R.Z., ESTRIN, Y., HORITA, Z., et al., "Producing bulk ultrafine-grained materials by severe plastic deformation", JOM, v. 58, n. 4, pp. 33-39, Apr. 2006.

[14] MATERIA, E.R., et al. "The Influence of Processing Conditions on Hardness Homogeneity Evolution in Commercially Pure Cast Aluminium Processed by Equal Channel Angular Pressing", Materia-Rio De Janeiro, v. 15, n. 2, pp. 265-269, Feb. 2010.

[15] VALIEV, R.Z., LANGDON, T.G. "Principles of equal-channel angular pressing as a processing tool for grain refinement", Progress in Materials Science, v. 51, n. 7, pp. 881-981, Sep. 2006.

[16] JOZEF, Z., SERGEY, D.V., GEORGE, R., et al., "Ultrafine grained structure development in steel with different initial structure by severe plastic deformation", Materia-Rio De Janeiro, v. 15, n. 2, pp. 258-264, Feb. 2010.

[17] SAFARI, M., JOUDAKI, J. "Effect of Temperature on Strength and Hardness in Multi-pass Equal Channel Angular Pressing (ECAP) of Aluminum Alloys", Transactions of the Indian Institute of Metals, v. 73, n. 3, pp. 619-627, March 2020.

[18] CARDOSO, E.K., GUIDO, V., SILVA, G., et al., "Microstructural evolution of AA7050 Al alloy processed by ECAP”, Materia-Rio De Janeiro, v. 15, n. 2, pp. 325-333, Feb. 2010.

[19] HUANG, H., LIU, H., WANG, C., et al., "Potential of multi-pass ECAP on improving the mechanical properties of a high-calcium-content Mg-Al-Ca-Mn alloy", Journal of Magnesium and Alloys, v. 7, n. 4, pp. 617-627, Dec. 2019.

[20] MENDES, A.A., ROVERE, C.A., KURI, S.E., et al., "A general study of commercially pure Ti subjected to severe plastic deformation: microstructure, strength and corrosion resistance", Materia-Rio De Janeiro, v. 15, n. 2, pp. 286-292, Feb. 2010.

[21] KOCH, C.C., OVID'KO, I.A., SEAL, S., et al., Structural nanocrystalline materials: Fundamentals and applications, 1 ed., Cambridge, Cambridge University Press, 2007.

[22] RAAB, G.J., VALIEV, R.Z., LOWE, T.C., et al., "Continuous processing of ultrafine grained Al by ECAP-Conform”, Materials Science and Engineering A, v. 382, n. 1-2, pp. 30-34, Feb. 2004.

[23] XU, C., SCHROEDER, S., BERBON, P.B., et al., "Principles of ECAP-Conform as a continuous process for achieving grain refinement: Application to an aluminum alloy", Acta Materialia, v. 58, n. 4, pp. 1379-1386, Apr. 2010.

[24] ISAZA MERINO, C.A., PELAEZ, D., FERNANDEZ-MORALES, P., et al., "Mechanical and microstructural behavior evolution of non-ferrous metals by ECASD", Materia-Rio De Janeiro. v. 22, n. 1, UNSP e11788, Jan. 2017

[25] NAIZABEKOV, A., VOLOKITINA, I, VOLOKITIN, A., et al., "Structure and Mechanical Properties of Steel in the Process "Pressing-Drawing". Journal of Materials Engineering and Performance, v. 28, n. 3, pp. 1762-1771, March 2019.

[26] NAIZABEKOV, A., LEZHNEV, S., PANIN, E., et al., "Effect of Combined Rolling-ECAP on U1trafine-Grained Structure and Properties in 6063 Al Alloy", Journal of Materials Engineering and Performance, v. 28. n. 1, pp. 200 - 210, Jan. 2019.

[27] GALKIN, S.P., "Radial shear rolling as an optimal technology for lean production", Steel in Translation, v. 44, n. 1, pp. 61-64, Jan. 2014.

[28] KARPOV, B.V., PATRIN, P.V., GALKIN, S.P., et al., "Radial-Shear Rolling of Titanium Alloy VT-8 Bars with Controlled Structure for Small Diameter Ingots $(\leq 200 \mathrm{~mm})$ ”, Metallurgist, v. 61, n. 9-10, pp. 884890 , Oct. 2018.

[29] SOROKIN, V.G., VOLOSNIKOVA, A.V., VYATKIN, S.A., Guide of steels and alloys, 2 ed., Moscow, Mechanical Engineering, 1989.

[30] KHARITONOV, V.A., USANOV, M.Y., "Methods for calculating deformation modes for radial-shear broaching”, Processing of solid and layered materials, v. 1, pp. 38-41, Jan. 2013.

[31] YADA, H., MATSUZU, N., NAKAJIMA, K., et al., "Strength and structural-changes under high strainrate hot deformation of C-Steels", Transactions ISIJ, v. 23, pp. 100-109, May 1983. 
[32] NAYZABEKOV, A., LEZHNEV, S., PANIN, E., et al., "Simulation of radial-shear rolling of austenitic stainless steel AISI-321", Journal of Chemical Technology and Metallurgy, v. 54, n. 5, pp. 1086-1094, Oct. 2019.

[33] NAIZABEKOV, A.B., LEZHNEV, S.N., PANIN, E.A. et al., "Computer simulation of microstructure evolution in radial-shear rolling using Simufact Forming software and Matilda material database”, In: Proceedings of the XIX International scientific conference «New technologies and achievements in metallurgy, material engineering, production engineering and physics», pp. 31-34, Częstochowa, June 2018.

[34] ANDRIEVSKY, R.A., Metal-based nanomaterials under extreme conditions, 1 ed., Moscow, Knowledge Laboratory, 2016.

[35] RYBALCHENKO, O.V., TOKAR, A.A., TERENTYEV, V et al., "Influence of equal-channel angular pressing in the temperature range of $200-400^{\circ} \mathrm{C}$ on the performance properties of steel $08 \mathrm{X} 18 \mathrm{~N} 10 \mathrm{~T}$ ", In: Proceedings of the VI All-Russian conference on nanomaterials with elements of a scientific school for young people, pp. 321-322, Moscow, May 2016.

\section{ORCID}

Abdrakhman Naizabekov

Sergey Lezhnev

Evgeniy Panin

Irina Volokitina

Andrey Kasperovich https://orcid.org/0000-0002-8517-3482

https://orcid.org/0000-0002-1737-9825

https://orcid.org/0000-0001-6830-0630

https://orcid.org/0000-0002-2190-5672

https://orcid.org/0000-0003-4403-6235 